\title{
Recombinant human erythropoietin alters gene expression and stimulates proliferation of MCF-7 breast cancer cells
}

\author{
Nina Trost ${ }^{1}$, Tina Stepisnik², Sabina Berne ${ }^{2}$, Anja Pucer $^{3}$, Toni Petan ${ }^{3}$, Radovan Komel ${ }^{2}$, \\ Natasa Debeljak ${ }^{1,2}$
${ }^{1}$ Center for Functional Genomics and Bio-chips, Institute of Biochemistry, Faculty of Medicine, University of Ljubljana, Slovenia
${ }^{2}$ Medical Center for Molecular Biology, Institute of Biochemistry, Faculty of Medicine, University of Ljubljana, Slovenia
${ }^{3}$ Department of Molecular and Biomedical Sciences, Jožef Stefan Institute, Ljubljana, Slovenia

Radiol Oncol 2013; 47(4): 382-389.

Received: 18 June 2013

Accepted: 16 August 2013

Correspondence to: Assist. Prof. Dr. Nataša Debeljak, Institute of Biochemistry, Faculty of Medicine University of Ljubljana, Vrazov trg 2 , SI-1000 Ljubljana, Slovenia. E-mail: natasa.debeljak@mf.uni-lj.si

Disclosure: No potential conflicts of interest were disclosed.

The paper was presented at the $7^{\text {th }}$ Conference of Experimental and Translational Oncology, 20-24 $4^{\text {th }}$ April 2013, Portoroz, Slovenia (www.ceto.si) co-organised and supported by COST TD1104 Action (www.electroporation.net).

Background. Functional erythropoietin (EPO) signaling is not specific only to erythroid lineages and has been confirmed in several solid tumors, including breast. Three different isoforms of erythropoietin receptor (EPOR) have been reported, the soluble (EPOR-S) and truncated (EPOR-T) forms acting antagonistically to the functional EPOR. In this study, we investigated the effect of human recombinant erythropoietin (rHUEPO) on cell proliferation, early gene response and the expression of EPOR isoforms in the MCF-7 breast cancer cell line.

Materials and methods. The MCF-7 cells were cultured with or without rHUEPO for $72 \mathrm{~h}$ or 10 weeks and assessed for their growth characteristics, expression of early response genes and different EPOR isoforms. The expression profile of EPOR and EPOR-T was determined in a range of breast cancer cell lines and compared with their invasive properties. Results. MCF-7 cell proliferation after rHUEPO treatment was dependent on the time of treatment and the concentration used. High rHUEPO concentrations $(40 \mathrm{U} / \mathrm{ml})$ stimulated cell proliferation independently of a preceding long-term exposure of MCF-7 cells to rHUEPO, while lower concentrations increased MCF-7 proliferation only after 10 weeks of treatment. Gene expression analysis showed activation of EGRI and FOS, confirming the functionality of EPOR. rHUEPO treatment also slightly increased the expression of the functional EPOR isoform, which, however, persisted throughout the 10 weeks of treatment. The expression levels of EPOR-T were not influenced. There were no correlations between EPOR expression and the invasiveness of MCF-7, MDA-MB-231, Hs578T, Hs578Bst, SKBR3, T-47D and MCF-10A cell lines.

Conclusions. rHUEPO modulates MCF-7 cell proliferation in time- and concentration-dependent manner. We confirmed EGR I, FOS and EPOR as transcription targets of the EPO-EPOR signaling loop, but could not correlate the expression of different EPOR isoforms with the invasiveness of breast cancer cell lines.

Key words: breast cancer; erythropoietin; erythropoietin receptor isoforms; proliferation; gene expression

\section{Introduction}

Erythropoietin (EPO) is a $34 \mathrm{kDa}$ glycoprotein hormone that regulates erythroid maturation in bone marrow. ${ }^{1}$ Its binding to the erythropoietin recep- tor (EPOR) on the surface of erythroid progenitors triggers several downstream signaling pathways, including Janus kinase 2 (Jak2)/signal transducer and activator of transcription 5 (STAT5), phosphatidylinositol 3-kinase (PI3K)/protein kinase 
TABLE 1. Details on the cohort of breast cancer cell lines as defined by ATCC. ESR, estrogen receptor; PGR, progesterone receptor; $A C$, adenocarcinoma; IDC, invasive ductal carcinoma; F, fibrocystic disease; PE, pleural effusion; $\mathrm{P}$. Br, primary breast. Cell invasiveness increases with number ( 1 = the least invasive, $7=$ the most invasive). Cells were cultured as described in Hevir et al. ${ }^{16}$

\begin{tabular}{|c|c|c|c|c|}
\hline Cell line & Receptor status & Tissue source & Tumor type & Invasiveness \\
\hline MCF-10A & $\mathrm{ESR}^{-}, \mathrm{PGR}^{-}$ & & $\mathrm{F}$ & 1 \\
\hline Hs578Bst & $\mathrm{ESR}^{-}, \mathrm{PGR}^{-}$ & Adjacent breast tissue & & 2 \\
\hline MCF-7 & $\mathrm{ESR}^{+}, \mathrm{PGR}^{+}$ & PE & IDC & 3 \\
\hline$T-47 D$ & $\mathrm{ESR}^{+}, \mathrm{PGR}^{+}$ & PE & IDC & 4 \\
\hline SK-BR-3 & ESR-, PGR-, HER2 ${ }^{+}$ & PE & $A C$ & 5 \\
\hline MDA-MB-231 & $\mathrm{ESR}^{-}, \mathrm{PGR}^{-}$ & PE & $A C$ & 6 \\
\hline Hs578T & $\mathrm{ESR}^{-}, \mathrm{PGR}^{-}$ & P. Br & IDC & 7 \\
\hline
\end{tabular}

B (Akt), Ras/mitogen-activated protein kinase (MAPK) and protein kinase C (PKC) pathways. $^{2}$ EPO-EPOR signaling not only promotes erythroid proliferation and differentiation, but also protects erythroid progenitors against apoptosis. ${ }^{3}$ EPO has been shown to increase the frequency of S-phase burst-forming-units (BFUs) in human bone marrow. ${ }^{4}$ Furthermore, EPO increases the expression of anti-apoptotic proteins B-cell lymphoma 2 (Bcl2 ) and B-cell lymphoma-extra large $\left(B c l-X_{L}\right)$ via the Jak2/STAT5 signaling pathway. ${ }^{5}$ Functional EPO-EPOR signaling is not limited only to erythroid lineages since EPOR expression has been confirmed in several non-hematopoietic cells and tissues, as well as in solid tumors. ${ }^{6}$ Recombinant forms of human erythropoietin (rHuEPO), used in clinical oncology settings to improve anemia, have been correlated with lower survival rates of patients undergoing rHuEPO treatment. ${ }^{2}$ These observations raised concerns about EPO's potential in promoting cancer growth and development of more aggressive cancer phenotypes. Therefore, EPO-EPOR signaling has been studied in correlation to cancer progression in several laboratories. Their findings are conflicting and strongly depend on the used experimental models, as rHuEPO was reported to increase cancer cell proliferation ${ }^{7,8}$ or to have no significant effect. ${ }^{9,10}$ Contrasting effects might be explained by the presence of different EPOR isoforms. Three EPOR isoforms are listed in the UniProt database (http://www.uniprot.org/ uniprot/P19235): a full-length functional (EPOR-F), a truncated isoform (EPOR-T) lacking the cytoplasmic region ${ }^{11}$ and a soluble (EPOR-S) receptor that is missing the trans-membrane and cytoplasmic domains. ${ }^{12}$ EPOR-S is secreted from the cell where it competes with EPOR-F for EPO binding. ${ }^{13}$ The EPOR-T and EPOR-S isoforms most probably act as antagonists of EPOR-mediated signaling. ${ }^{14}$ All three isoforms were confirmed in breast cancer. ${ }^{15}$

The objective of our study was to investigate the effect of rHuEPO on cell proliferation, EPOR expression and early gene response in breast cancer cells. The effect of a long-term rHuEPO treatment of MCF-7 cells on cell proliferation, EPOresponsiveness and the expression of functional (EPOR), soluble (EPOR-S) and truncated (EPOR-T) receptor isoforms was assessed. Additionally, the expression profile of EPOR and EPOR-T was determined in a range of breast cancer cell lines and compared with their invasive properties.

\section{Materials and methods}

\section{Cell lines}

The breast cancer cell lines (Table 1) were from the American Type Culture Collection (ATCC; Manassas, VA, USA) and were cultured according to their recommendations in basic growth medium, supplemented with $10 \%$ fetal bovine serum (FBS) at $37^{\circ} \mathrm{C}$ in a humidified $5 \%(\mathrm{v} / \mathrm{v}) \mathrm{CO}_{2}$ atmosphere. The receptor status of a specific cell line and the tumor type are shown in Table 1 . The MCF-7 cells were pretreated with rHuEPO up to 10 weeks (5 U/ ml, NeoRecormon, Roche, Germany). In parallel, control cells were cultured in the same conditions, but without $\mathrm{rHuEPO}$.

\section{Proliferation assays}

The effect of rHuEPO on cell proliferation was analyzed using the colorimetric 3-(4,5-dimethylthiazol-2-yl)-2,5-diphenyltetrazolium bromide (MTT, Sigma, USA) assay. rHuEPO pretreated (10 weeks) and non-pretreated cells were seeded in a volume 
TABLE 2. Primers used in GPCR analysis of genes of interest and reference genes. Forward (FW) and reverse (Rev) reverse oligonucleotide primers are shown; (NA) not available

\begin{tabular}{|c|c|c|c|c|c|}
\hline \multicolumn{6}{|c|}{ Genes of interest } \\
\hline Gene symbol & Gene name & Nucleotide sequence & Ref. seq. & Amplicon length & PCR Eff \\
\hline EPOR & & $\begin{array}{l}\text { Fw: 5'-GCTGGAAGTTACCCTTGTGG-3' } \\
\text { Rev: 5'-CTCATCCTCGTGGTCATCCT-3' }\end{array}$ & NM_000121 & 148 & 1.920 \\
\hline EPOR-S & $\begin{array}{l}\text { erythropoietin receptor, } \\
\text { soluble form }\end{array}$ & $\begin{array}{l}\text { FW: 5'-CTCCACCCTCTGTACGCTCCCTGC-3' } \\
\text { Rev: 5'- ACGCCTAGCGGGCTCTGAAGC-3' }\end{array}$ & NM_000121 & 183 & (NA) \\
\hline JUN & jun-proto oncogene & $\begin{array}{l}\text { Fw: 5'-CCAAAGGATAGTGCGATGTTT-3' } \\
\text { Rev: 5'-CTGTCCCTCTCCACTGCAAC-3' }\end{array}$ & NM_002228.2 & 62 & 2 \\
\hline NF-KB & $\begin{array}{l}\text { nuclear factor } \\
\text { of kappa light } \\
\text { polypeptide gene } \\
\text { enhancer in B-cells } 1\end{array}$ & $\begin{array}{l}\text { Fw: 5'-GGTGCCTCTAGTGAAAAGAACAAGA-3' } \\
\text { Rev: 5'-GCTGGTCCCACATAGTTGCA-3' }\end{array}$ & NM_003998.3 & 68 & 1.722 \\
\hline \multicolumn{6}{|c|}{ Reference genes } \\
\hline Gene symbol & Gene name & Nucleotide sequence & Ref. seq. & Amplicon length & Primer Eff \\
\hline RPLPO & $\begin{array}{l}\text { ribosomal protein, } \\
\text { large, PO }\end{array}$ & $\begin{array}{l}\text { Fw: 5'-TCTACAACCCTGAAGTGCTTGAT-3' } \\
\text { Rev: 5'-CAATCTGCAGACAGACACTGG-3' }\end{array}$ & NM_001002.3 & 96 & 2.073 \\
\hline GAPDH & $\begin{array}{l}\text { glyceraldehyde- } \\
\text { 3-phosphate } \\
\text { dehydrogenase }\end{array}$ & $\begin{array}{l}\text { Fw: 5'-AGCCACATCGCTCAGACAC-3' } \\
\text { Rev: 5'-GCCCAATACGACCAAATCC-3' }\end{array}$ & NM_002046.3 & 66 & 1.999 \\
\hline SF3A1 & $\begin{array}{l}\text { Splicing factor 3a, } \\
\text { subunit } 1\end{array}$ & NA & NM_005877 & NA & 1.799 \\
\hline TOP1 & DNA Topoisomerase I & $\begin{array}{l}\text { Fw: 5'-CCCTGTACTTCATCGACAAGC-3' } \\
\text { Rev: 5'-CCACAGTGTCCGCTGTTTC-3' }\end{array}$ & NM_003286.2 & NA & 1.809 \\
\hline
\end{tabular}

of $100 \mu \mathrm{l}$ on a 96-well plate at a density of $5 \times 10^{3}$ cells per well. Cells seeded in six replicates were left to adhere for $24 \mathrm{~h}$. Growth medium was then replaced with a medium supplemented with different concentrations of $\mathrm{rHuEPO}(0,5,40 \mathrm{U} / \mathrm{ml})$. Cells were grown for $72 \mathrm{~h}$ and at specific time-points 15 $\mu \mathrm{l}$ of MTT ( $5 \mathrm{mg} / \mathrm{ml}$ in PBS) was added to each well and the plate was incubated at $37^{\circ} \mathrm{C}$ for $3 \mathrm{~h}$, according to the manufacturer's recommendations. Cell metabolic activity reflecting cell number and thus proliferation was measured daily and normalized to values obtained with control cells not exposed to $\mathrm{rHuEPO}$.

\section{Gene expression analysis}

Sample preparation. MCF-7 cells pretreated with rHuEPO for 10 weeks (Figure 1C) and non-pre- treated cells (Figure 1A) were cultured in basic growth medium in T-25 flasks at a density of $5 \mathrm{x}$ $10^{5}$ cells $/ \mathrm{ml}$ and grown to $75 \%$ of confluency. Cells were serum starved for $24 \mathrm{~h}$ and exposed to $50 \mathrm{U} /$ $\mathrm{ml} \mathrm{rHuEPO}$ for $0,4,8,16,32$ and $64 \mathrm{~min}$. Following the stimulation with $\mathrm{rHuEPO}$, cells were subjected to RNA isolation and analyzed for EPOR expression levels. The non-pretreated cells were further analyzed for early gene response. Cells were cultured in 6-well plates at a density of $3 \times 10^{5}$ cells/ $\mathrm{ml}$ in serum-deprived media and cultured for 48 h. Cells were stimulated with $5 \mathrm{U} / \mathrm{ml} \mathrm{rHuEPO} \mathrm{for}$ 0, 30, 60 and $240 \mathrm{~min}$, fast frozen in liquid nitrogen and subjected to RNA isolation (Figure 1B).

RNA isolation. Total RNA was isolated using the High Pure Total RNA Isolation Kit (Roche) or TRI Reagent (Sigma) following manufacturer's instructions. The Agilent Bioanalyzer 2100 (Agilent 
Technologies, USA) was used for the determination of RNA concentrations and quality, assuring all RNA integrity numbers (RINs) were above 9.8. Total RNA was transcribed to cDNA using Transcriptor First Strand cDNA Synthesis Kit (Roche) and SuperScript III reverse transcriptase (Invitrogen, USA).

Quantitative real-time $P C R \quad(q P C R)$. Forward and reverse primers for FOS, JUN, NFKB, FOSL1, EGR1, RPLPO and GAPDH were designed to span intron-exon junctions using PrimerExpress software (Applied Biosystems, USA) and their specificity was checked using BLAST algorithm (Table 2). RPLPO and GAPDH were used as reference genes in the analysis of early gene response. Forward and reverse primers for functional (EPOR), soluble $(E P O R-S)$ and truncated (EPOR-T) erythropoietin receptor were designed according to Arcasoy et al. ${ }^{15}$ Primers specific for SF3A1 and YWHAZ genes from the Human geNorm Kit (Primer Design, UK) and for $T O P 1^{17}$ were chosen as reference genes in the analysis of the EPOR isoform expression. Primer validation was done by analyzing the slope of the standard curve and the presence of a single peak in the melting curve after qPCR analysis. qP$\mathrm{CR}$ was conducted on a 384-well plates using the LightCycler 480 Real-Time PCR System (Roche) and SYBR Green I Master chemistry (Roche). Amplification of specific PCR products was performed in triplicates in a total reaction mixture of 5 $\mu \mathrm{l}$, containing $750 \mathrm{ng}$ RNA equivalent cDNA template and $300 \mathrm{nM}$ of each set of primers. The expression levels of the selected reference genes were used for normalization of expression data. Gene expression normalization factors were calculated for each sample based on geometric means of the selected reference genes. ${ }^{18}$ Minimum Information for Publication of Quantitative Real-Time PCR Experiments (MIQE) was followed in the performance and interpretation of the qPCR reactions. ${ }^{19}$

\section{EPOR expression and cancer invasiveness}

The invasiveness of breast cancer cell lines was compared with the expression of EPOR isoforms. Cell lines differing in cell invasiveness as represented in Table 1.

\section{Statistical analysis}

Statistical analysis of the data was performed using the Limma package ${ }^{20}$ from Bioconductor analysis tools for R programming language..$^{21}$ The effect of rHuEPO treatment on cell proliferation and gene

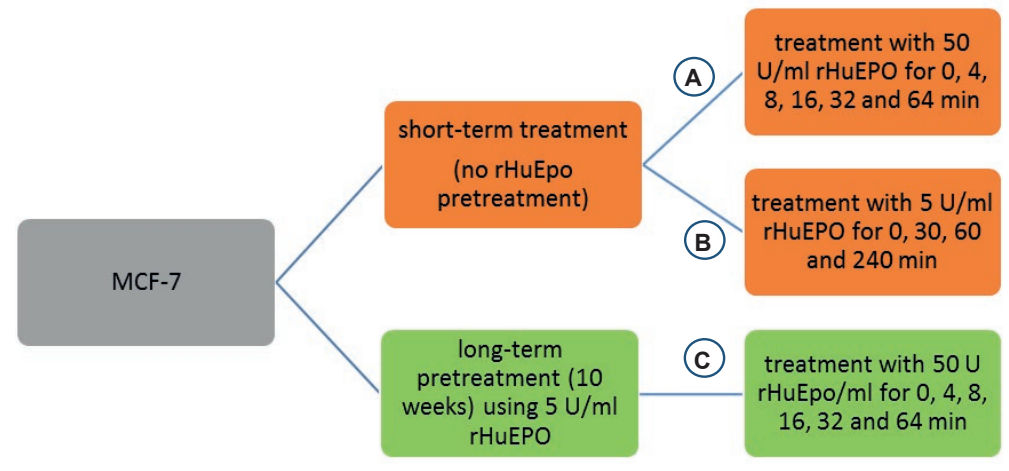

FIGURE 1. Protocol of treatment of MCF-7 cells with recombinant human erythropoietin for isolation of total RNA.

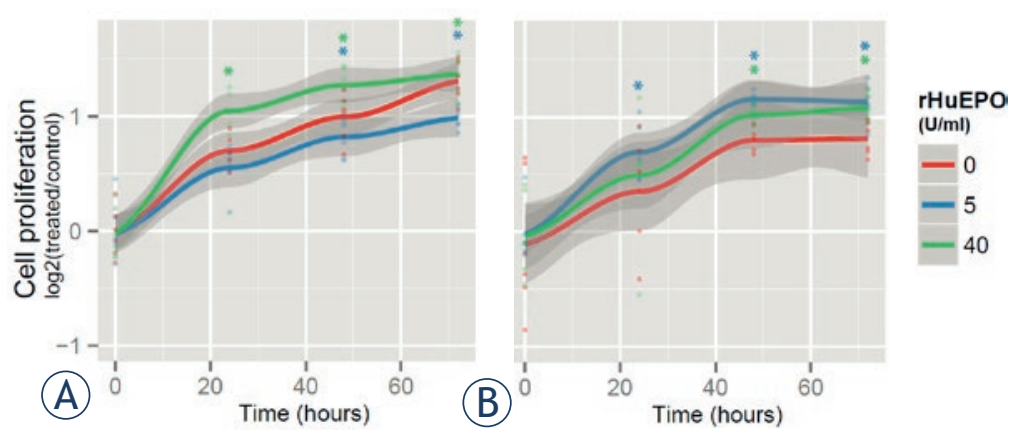

FIGURE 2. Differential effects of recombinant human EPO on MCF-7 cell proliferation (A) MCF-7 cells were cultured in complete medium in the presence of indicated concentrations of rHUEPO (short-term treated) (B) MCF-7 cells were cultured in complete medium in the presence of $5 \mathrm{U} / \mathrm{ml}$ of rHuEPO for 10 weeks (longterm pretreated cells), EPO was added to the pretreated cells at indicated concentrations. Asterisk $\left({ }^{*}\right)$ denotes statistical significance for Type 1 error $a=0.05$.

expression was assessed by Two-way analysis of variance (ANOVA). Multiple-testing correction using False discovery rate (FDR) ${ }^{22}$ was employed and $\mathrm{p}<0.05$ was considered as statistically significant.

\section{Results}

\section{EPO alters the proliferation rate of MCF-7 breast cancer cells}

MCF-7 cells were stimulated with $\mathrm{rHuEPO}(0,5,40$ $\mathrm{U} / \mathrm{ml}$ ) and assessed for proliferation using the MTT assay. We found that MCF-7 cell proliferation is dependent on the concentration of rHuEPO used and the time of the treatment (Figure 2). Treatments with $40 \mathrm{U} / \mathrm{ml} \mathrm{rHuEPO}$ led to increased MCF-7 cell proliferation independently of the length of cell exposure to rHuEPO. On the other hand, $5 \mathrm{U} / \mathrm{ml}$ rHuEPO affects MCF-7 cell proliferation in a time dependent manner; cell proliferation was reduced 
EPOR

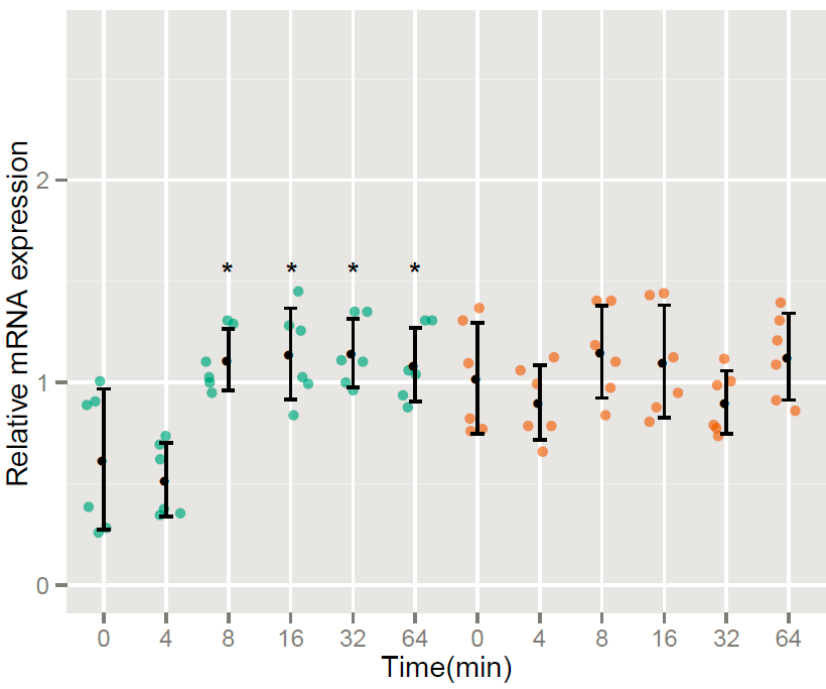

EPOR - T

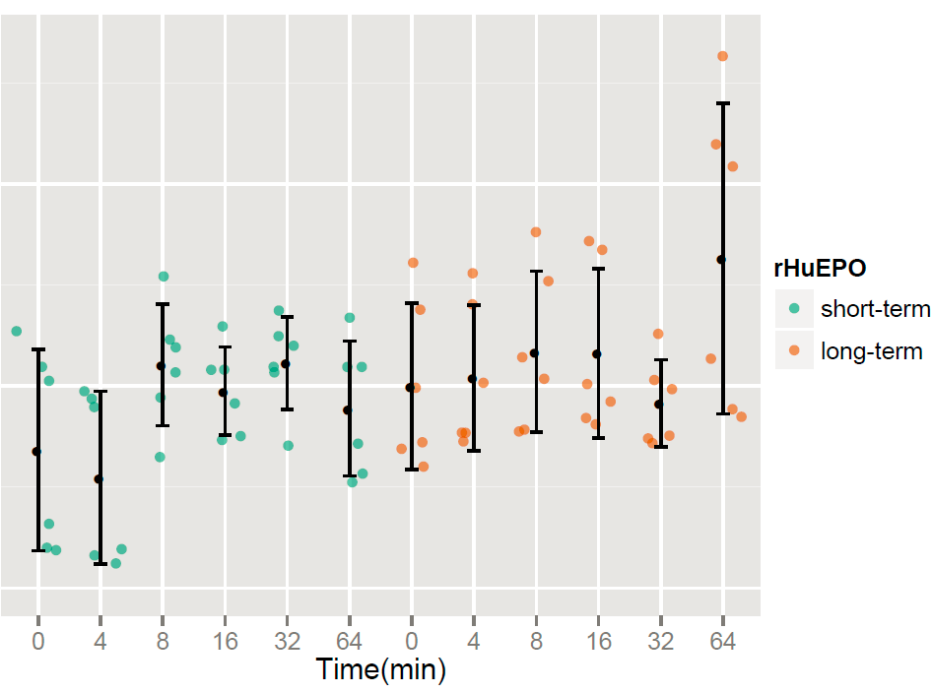

FIGURE 3. Effects of recombinant human EPO on relative EPOR and EPOR-T expression. MCF-7 cells were stimulated with $50 \mathrm{U} / \mathrm{ml} \mathrm{rHUEPO} / \mathrm{short-term}$, green) or cultured in complete medium in the presence of $5 \mathrm{U} / \mathrm{ml}$ of rHuEPO for 10 weeks and stimulated with $50 \mathrm{U} / \mathrm{ml} \mathrm{rHuEPO}$ (long-term, red). Error bars represent standard deviations (SD) between six replicate samples; asterisk (*) denotes statistical significance for Type 1 error $a=0.05$.

during a short-term treatment (Figure 2A), but was higher when rHuEPO was added to long-term rHuEPO-pretreated cells (Figure 2B).

\section{EPO induces gene expression changes in MCF-7 cells}

The expression of EPOR isoforms in EPO-treated cells. To determine the effects of rHuEPO on the expression of its receptor protein variants, mRNA expression levels of EPOR, EPOR-S and EPOR-T genes were analyzed in short (Figure $1 \mathrm{~A}$ ) and long-term (Figure 1C) rHuEPO-treated MCF-7 cells. The expression of EPOR and EPOR-T isoforms at specific time-points was confirmed by qPCR (Figure 3 ). On the other hand, we were not able to confirm the presence of EPOR-S (data not show). Short-term stimulation of MCF-7 cells with $50 \mathrm{U} / \mathrm{ml} \mathrm{rHuEPO}$ leads to an increase in $E P O R$ expression, while it has no statistically significant effect on EPOR-T. Interestingly, the addition of $50 \mathrm{U} / \mathrm{ml} \mathrm{rHuEPO}$ to the long-term pretreated cells ( $5 \mathrm{U} / \mathrm{ml} \mathrm{rHuEPO}$ ) did not have any additional influence on the expression levels of EPOR and EPOR-T.

The expression of early response genes in EPOtreated cells. Since rHuEPO affected MCF-7 cell proliferation in a time-dependent manner only at the $5 \mathrm{U} / \mathrm{ml}$ concentration, MCF-7 cells were stimulated with $5 \mathrm{U} / \mathrm{ml} \mathrm{rHuEPO}$ and analyzed for early gene response. The most pronounced changes were observed in the expression of EGR1 and FOS (Figure 4). Both genes were up-regulated after
rHuEPO stimulation. rHuEPO only slightly modulated the expression of FOSL1, JUN and NF- $K B$ genes.

\section{The expression of EPOR does not correlate with breast cancer cell invasiveness}

The expression of EPOR isoforms was paralleled with the invasiveness of cancer and epitheliallike breast cell lines included in the current study (Table 1). We found no association between the expression of EPOR (EPOR or EPOR-T) and the breast cell invasiveness. There were no significant differences in the level of EPOR expression between cell lines and its expression in a particular cell line did not correlate with its invasiveness, ESR, PGR or HER2 status (Figure 5).

\section{Discussion}

$\mathrm{EPO}$ is a key regulator of erythropoiesis and is gaining more significance also in other tissues ${ }^{2,6}$ and (patho)physiological processes. EPO is important for neuro- ${ }^{23}$ and cardioprotection ${ }^{24}$, while the functionality of EPO-EPOR signaling in cancer settings questions the suitability of its usage for the treatment of cancer or chemotherapy-related anemia. ${ }^{25}$ EPOR activation is considered to influence cancer cell growth in terms of stimulated proliferation, prevention of apoptosis and increased resist- 

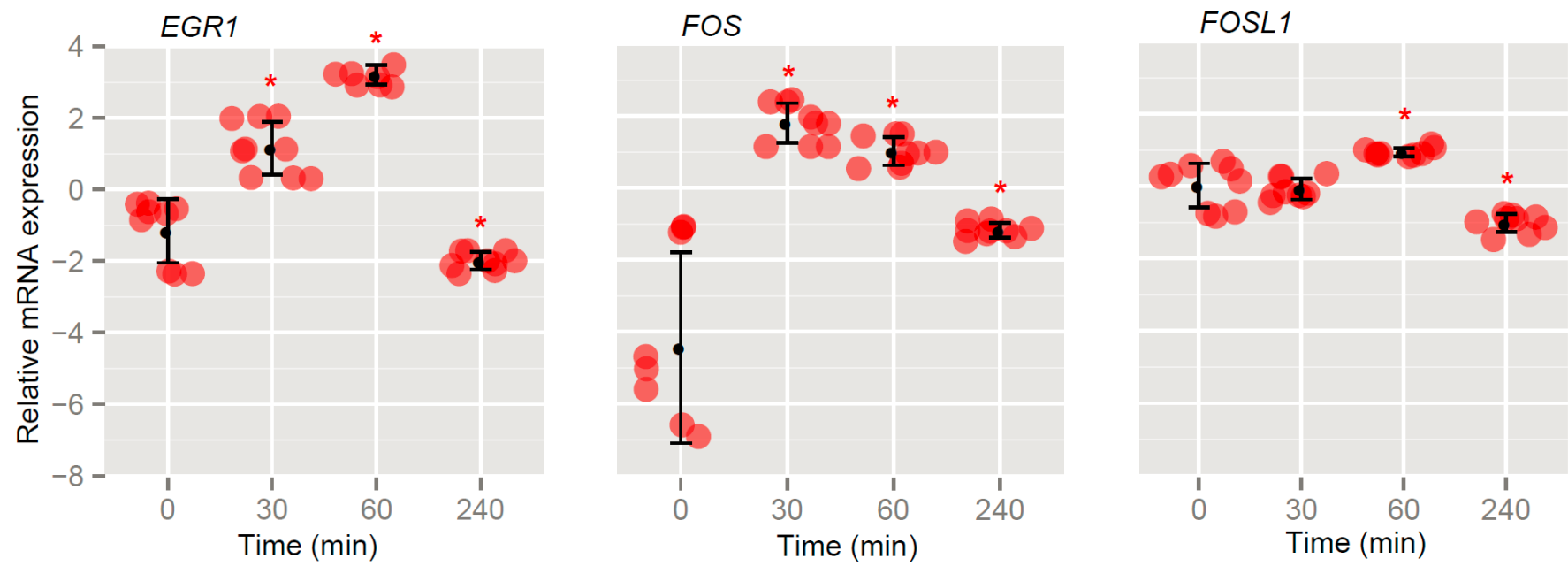

FIGURE 4. Early gene response upon rHUEPO stimulation of MCF-7 cells. The expression of EGRI, FOS, FOSLI, JUN and $N F-K B$ was determined at the indicated time-points during rHuEPO treatment (5 U/ml) of MCF-7 cells grown in serumstripped growth medium. Error bars represent standard deviations (SD) determined from six replicate samples; asterisk $\left({ }^{*}\right)$ denotes statistical significance for Type 1 error $a=0.05$.
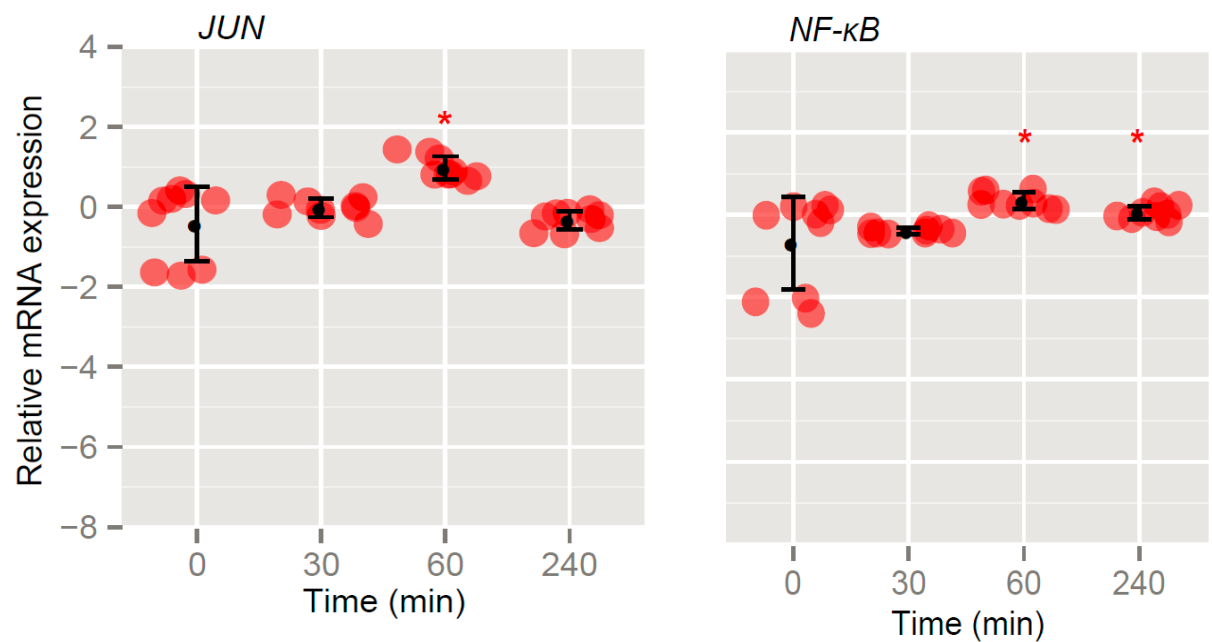

ance to therapy. The mechanisms of EPO actions are not well understood, but it has been suggested that an active crosstalk with other growth factor receptors is involved, especially those from the estrogen family and HER2. ${ }^{26,27}$ It has been shown that the AP-1 (FOS and JUN) transcription factor is critical for growth and proliferation of breast cancer cells. ${ }^{28}$ We therefore analyzed early gene response in MCF-7 cells stimulated with rHuEPO. We show that $\mathrm{rHuEPO}$ induces rapid up-regulation of FOS and EGR1 gene expression, which is followed by an increase in the expression of $J U N$ and $N F-\kappa B$ (Figure 4). Despite the up-regulation of $F^{2} S^{29}$ and $E G R 1^{30}$ genes, both considered a driving force for cell proliferation, we observed a decreased proliferation rate of short-term (72 h) treated MCF-7 cells after stimulation with $\mathrm{rHuEPO}(5 \mathrm{U} / \mathrm{ml}$ ) (Figure 2). On the contrary, the effect was reversed after longterm pretreatment being in agreement with our previously published data. ${ }^{31}$ This suggests that a long-term treatment with low doses of rHuEPO

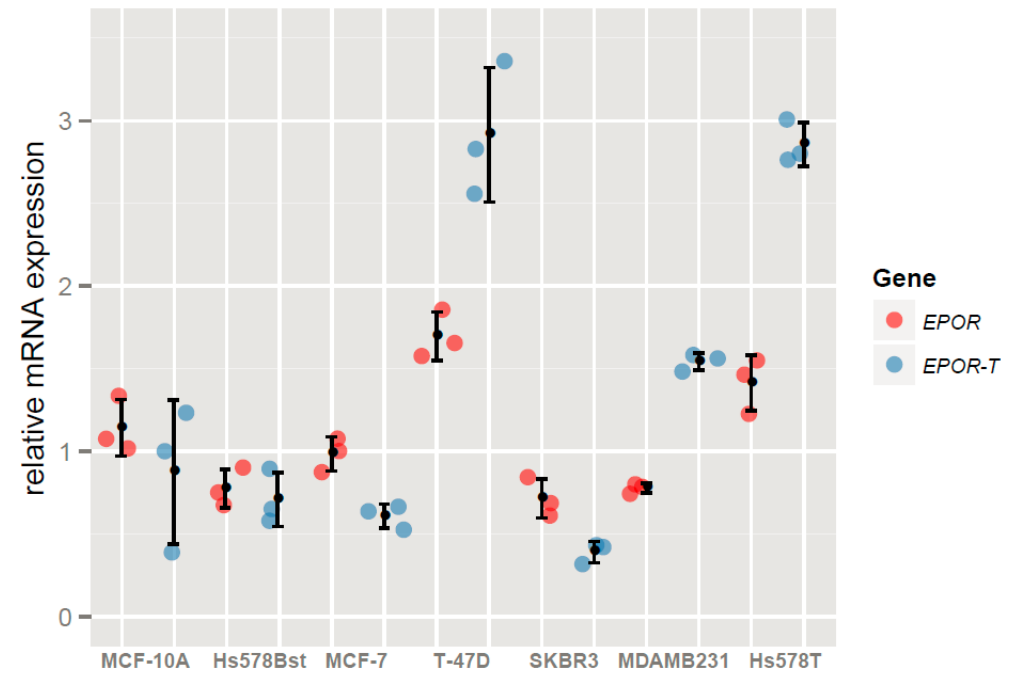

FIGURE 5. Expression of EPOR isoforms in different breast cancer cell lines; expression of functional EPOR (red); expression of truncated form of EPOR-T (blue). Cell lines differ in the level of invasiveness with MCF-10A cell line being the least invasive and Hs578T cell line being the most invasive (Table 1). Error bars represent standard deviations (SD) of the relative expression values determined in triplicate samples. 
sensitizes the MCF-7 cells to further treatment with the growth factor. At a higher concentration of 40 $\mathrm{U} / \mathrm{ml}$, $\mathrm{rHuEPO}$ significantly increased cell proliferation independently of the any previous exposure of MCF-7 cells to the hormone.

Further, we analyzed the expression of functional EPOR and its antagonists, truncated (EPOR-T) and soluble EPOR (EPOR-S), in rHuEPO-treated MCF-7 cells and other breast cancer cell lines. The presence of EPOR-S was not confirmed, despite previous reports of its presence in MCF-7 cells. ${ }^{32}$ We found no association between the expression of EPOR (EPOR or EPOR-T) and the breast cell invasiveness. There were no significant differences in the level of EPOR expression between cell lines and its expression in a particular cell line did not correlate with its invasiveness, ESR, PGR or HER2 status (Figure 5).

Interestingly, we show here that $\mathrm{rHuEPO}$ can slightly up-regulate the expression of the functional EPOR, but has no effect on EPOR-T. The upregulation of functional $E P O R$ is very fast, it happens after $8 \mathrm{~min}$ of $\mathrm{rHuEPO}(50 \mathrm{U} / \mathrm{ml})$ stimulation. The addition of $50 \mathrm{U} / \mathrm{ml} \mathrm{rHuEPO}$ to the long-term pretreated cells (5 U/ml rHuEPO) did not have any additional influence on the EPOR expression levels. It seems the expression is slightly elevated throughout whole long-term treatment (Figure 3). Our results indicate that $\mathrm{rHuEPO}$ stimulation regulates the expression of EPOR but not EPOR-T in MCF-7 cells as indicated previously. ${ }^{33}$ Finally, the analysis of EPOR mRNA levels in a panel of breast cancer cell lines suggests that the pattern of EPOR (functional and EPOR-T) expression does not correlate with the invasiveness of breast cancer cell lines (Figure 5).

\section{Conclusions}

Our study confirmed the functionality of EPOEPOR signaling pathways in MCF-7 cells, indicating time- and concentration-dependent $\mathrm{rHuEPO}$ effects on cell proliferation. The $5 \mathrm{U} / \mathrm{ml}$ (physiological) $\mathrm{rHuEPO}$ concentration was shown to have an opposite effect on cell proliferation after 10 weeks versus 72 hours of treatment, most probably due to cell line sensibilization. Furthermore, two EPOR isoforms were confirmed, full-length functional $E P O R$ and truncated EPOR-T, showing different expression profile upon rHuEPO treatment. The observed expression profiles are not correlated with the invasiveness of analyzed breast cancer cell lines.

\section{Acknowledgement}

Authors acknowledge the financial support of the Slovenian Research Agency; the study was supported by the P1-0104 and P1-0207 program grants, Z3-9402 grant to S.B., J3-0124 grant to N.D., and Young Researcher Grant to N.T. Authors also acknowledge Roche Slovenia for financial support.

\section{Footnotes}

Tina Stepišnik is currently employed at the Laboratory of Biocybernetics, Faculty of Electrical Engineering, University of Ljubljana, Slovenia.

\section{Authors' contrubutions}

SB, NT, ND, TP and RK contributed to the conception and design of the study. SB and TS carried out the cell proliferation and invasiveness experiments, the gene expression was assayed by SB, TS and NT. Total RNA from the cells with different invasiveness was provided by TP and AP. SB, TS, NT and ND have analyzed the data and interpreted the results. NT, TS and ND participated in drafting the article. All authors critically revised the manuscript and approved the submitted and revised version.

\section{References}

1. Moritz KM, Lim GB, Wintour EM. Developmental regulation of erythropoietin and erythropoiesis. Am J Physiol 1997; 273: R1829-44.

2. Jelkmann W, Bohlius J, Hallek M, Sytkowski AJ. The erythropoietin receptor in normal and cancer tissues. Crit Rev Oncol Hematol 2008; 67: 39-61.

3. Koury MJ, Bondurant MC. The molecular mechanism of erythropoietin action. Eur J Biochem 1992; 210: 649-63.

4. Dessypris EN, Krantz SB. Effect of pure erythropoietin on DNA-synthesis by human marrow day 15 erythroid burst forming units in short-term liquid culture. Br J Haematol 1984; 56: 295-306.

5. Silva M, Grillot D, Benito A, Richard C, Nunez G, Fernandez-Luna IL. Erythropoietin can promote erythroid progenitor survival by repressing apoptosis through Bcl-XL and Bcl-2. Blood 1996; 88: 1576-82.

6. Elliott $\mathrm{S}$, Sinclair AM. The effect of erythropoietin on normal and neoplastic cells. Biologics 2012; 6: 163-89.

7. Westenfelder C, Baranowski RL. Erythropoietin stimulates proliferation of human renal carcinoma cells. Kidney Int 2000; 58: 647-57.

8. Kumar SM, Acs G, Fang D, Herlyn M, Elder DE, Xu XW. Functional erythropoietin autocrine loop in melanoma. Am J Pathol 2005; 166: 823-30.

9. Selzer E, Wacheck V, Kodym R, Schlagbauer-Wadl H, Schlegel W, Pehamberger $\mathrm{H}$, et al. Erythropoietin receptor expression in human melanoma cells. Melanoma Res 2000; 10: 421-6.

10. Ludwig $\mathrm{H}$. rHuEPO and treatment outcomes: the preclinical experience. Oncologist 2004; 9 (Suppl 5): 48-54. 
11. Nakamura Y, Komatsu N, Nakauchi H. A truncated erythropoietin receptor that fails to prevent programmed cell death of erythroid cells. Science 1992; 257: $1138-41$.

12. Todokoro K, Kuramochi S, Nagasawa T, Abe T, Ikawa Y. Isolation of a cDNA encoding a potential soluble receptor for human erythropoietin. Gene 1991; 106: 283-4.

13. Sakanaka M, Wen TC, Matsuda S, Masuda S, Morishita E, Nagao M, et al. In vivo evidence that erythropoietin protects neurons from ischemic damage. Proc Natl Acad Sci U S A 1998; 95: 4635-40.

14. Sinclair AM, Todd MD, Forsythe K, Knox SJ, Elliott S, Begley CG. Expression and function of erythropoietin receptors in tumors: implications for the use of erythropoiesis-stimulating agents in cancer patients. Cancer 2007 110: $477-88$

15. Arcasoy MO, Amin K, Karayal AF, Chou SC, Raleigh JA, Varia MA, et al. Functional significance of erythropoietin receptor expression in breast cancer. Lab Invest 2002; 82: 911-8.

16. Hevir N, Trost N, Debeljak N, Rizner TL. Expression of estrogen and progesterone receptors and estrogen metabolizing enzymes in different breast cancer cell lines. Chem Biol Interact 2011; 191: 206-16.

17. Mounier CM, Wendum D, Greenspan E, Flejou JF, Rosenberg DW, Lambeau $G$. Distinct expression pattern of the full set of secreted phospholipases A2 in human colorectal adenocarcinomas: SPLA2-III as a biomarker candidate. Br J Cancer 2008; 98: 587-95.

18. Vandesompele J, De Preter K, Pattyn F, Poppe B, Van Roy N, De Paepe $A$, et al. Accurate normalization of real-time quantitative RT-PCR data by geometric averaging of multiple internal control genes. Genome Biol 2002; 3: RESEARCH0O34.

19. Bustin SA, Benes V, Garson JA, Hellemans J, Huggett J, Kubista M, et al. The MIQE guidelines: minimum information for publication of quantitative realtime PCR experiments. Clin Chem 2009; 55: 611-22.

20. Smyth GK. Limma: linear models for microarray data. In: Robert Gentleman VJC, Wolfgang Huber, Rafael A. Irizarry, Sandrine Dudoit editor. Bioinformatics and computational biology solutions using $R$ and bioconductor. New York: Springer; 2005. p.397-420.

21. (2008) RDCT. R: A language and environment for statistical computing. Vienna: R Fundation for Statistical Computing; 2011.

22. Benjamini Y. Hochberg Y. Controlling the false discovery rate - a practical and powerful approach to multiple testing. $R$ Stat Soc Series B Stat Methodol 1995; 57: 289-300.

23. Noguchi $C T$, Asavaritikrai $P$, Teng $R$, Jia Y. Role of erythropoietin in the brain Crit Rev Oncol Hematol 2007; 64: 159-71.

24. Nishiya D, Omura T, Shimada K, Matsumoto R, Kusuyama T, Enomoto $S$, et al. Effects of erythropoietin on cardiac remodeling after myocardial infarction. J Pharmacol Sci 2006; 101: 31-9.

25. Szenajch J, Wcislo G, Jeong JY, Szczylik C, Feldman L. The role of erythropoietin and its receptor in growth, survival and therapeutic response of human tumor cells From clinic to bench - a critical review. Biochim Biophys Acto 2010; 1806: 82-95.

26. Liang K, Esteva FJ, Albarracin C, Stemke-Hale K, Lu Y, Bianchini G, et al. Recombinant human erythropoietin antagonizes trastuzumab treatment of breast cancer cells via Jak2-mediated Src activation and PTEN inactivation. Cancer Cell 2010; 18: 423-35.

27. Trost N, Hevir N, Rizner TL, Debeljak N. Correlation between erythropoietin receptor(s) and estrogen and progesterone receptor expression in different breast cancer cell lines. Int J Mol Med 2013; 31: 717-25.

28. Lu C, Shen Q, DuPre E, Kim H, Hilsenbeck S, Brown PH. cFos is critical for MCF-7 breast cancer cell growth. Oncogene 2005; 24: 6516-24.

29. Liu WM, Powles T, Shamash J, Propper D, Oliver T, Joel S. Effect of haemopoietic growth factors on cancer cell lines and their role in chemosensitivity. Oncogene 2004; 23: 981-90.

30. Vivacqua A, Bonofiglio D, Recchia AG, Musti AM, Picard D, Ando S, et al. The G protein-coupled receptor GPR30 mediates the proliferative effects induced by 17beta-estradiol and hydroxytamoxifen in endometrial cance cells. Mol Endocrinol 2006; 20: 631-46.

31. Trost N, Juvan P, Sersa G, Debeljak N. Contrasting effect of recombinant human erythropoietin on breast cancer cell response to cisplatin induced cytotoxicity. Radiol Oncol 2012; 46: 213-25.
32. Arcasoy MO, Jiang X, Haroon ZA. Expression of erythropoietin receptor splice variants in human cancer. Biochem Biophys Res Commun 2003; 307: 999-1007.

33. Singh S, Dev A, Verma R, Pradeep A, Sathyanarayana P, Green JM, et al. Defining an EPOR- regulated transcriptome for primary progenitors, including Tnfr-sf13c as a novel mediator of EPO- dependent erythroblast formation. PLoS One 2012; 7: e38530. 